\title{
Effect of low gravity on water removal inside proton exchange membrane fuel cells (PEMFCs) with different flow channel configurations
}

\author{
Hang Guo ${ }^{\text {a, c, }{ }^{*}, \text { Xuan Liu }}{ }^{\text {a }}$, Jian Fu Zhao ${ }^{\text {b }}$, Fang Ye ${ }^{a}$, Chong Fang Ma ${ }^{a}$ \\ ${ }^{a}$ MOE Key Laboratory of Enhanced Heat Transfer and Energy Conservation, and Beijing Key Laboratory of Heat Transfer and Energy Conversion, College of \\ Environmental and Energy Engineering, Beijing University of Technology, Beijing 100124, China \\ ${ }^{\mathrm{b}}$ Institute of Mechanics, Chinese Academy of Sciences, Beijing 100080, China \\ ${ }^{\mathrm{c}}$ Collaborative Innovation Center of Electric Vehicles in Beijing, Beijing 100081, China
}

\section{A R T I C L E I N F O}

\section{Article history:}

Received 31 March 2016

Received in revised form

29 June 2016

Accepted 1 July 2016

Available online 5 August 2016

\section{Keywords:}

Microgravity

PEMFC

Flow channel configuration

Water removal

Flooding

\begin{abstract}
A B S T R A C T
Practically investigate water removal and cell performance for PEMFCs under low gravity circumstance is an urgent task, especially as a promising power supply unit applied to space engineering. PEMFC with an in-situ optical flow field was used to explicate two-phase flow and water removal inside cathode flow field from terrestrial gravity to microgravity. The cell was tested in the vertical and horizontal flow channel orientations. A 3.6 s short-time micro-gravity circumstance was provided by National Microgravity Laboratory. Results show that gravitational level has an essential influence on gas-liquid twophase flow characteristics for PEMFC with different configurations. The cell placed in different channel orientations also shows distinguished operating behavior because of the complicated impact of the changed gravity and configuration. Under the operating condition of a vertical flow channel orientation, accumulated water and droplets in terrestrial are pushed by oxygen flow to continuous removal toward the outlet of the fuel cell to alleviate water flooding, and the cell performance is slightly enhanced in a $3.6 \mathrm{~s}$ micro-gravity circumstance. Operating in a horizontal flow channel orientation, the generated water throughout the micro-gravity circumstance duration is not prone to move and flood flow channels in micro-gravity, meanwhile the cell performance is slightly deteriorated.
\end{abstract}

() 2016 Elsevier Ltd. All rights reserved.

\section{Introduction}

PEMFCs, also known as polymer electrolyte membrane fuel cells, are typical devices that can continuously convert chemical energy into electric energy and a limited amount of thermal energy. Since the 1960s, PEMFC with polystyrene has been successfully applied in space engineering, particularly to the GEMINI spacecraft $[1,2]$. In recent decades, PEMFC has been recognized as a promising alternative power supply equipment for short-term space missions because of technical innovation and their distinguishing features, such as high energy efficiency, clear and regenerative operation [3-7]. To enhance the cell performance of PEMFC for space

\footnotetext{
* Corresponding author. MOE Key Laboratory of Enhanced Heat Transfer and Energy Conservation, and Beijing Key Laboratory of Heat Transfer and Energy Conversion, College of Environmental and Energy Engineering, Beijing University of Technology, Beijing 100124, China.

E-mail address: hangguo@sohu.com (H. Guo).
}

application, a series of investigations has been conducted in a simulated closed environment; these investigations included the life test of the PEMFC and the effects of fuel and oxygen humidity on PEMFC behavior [1,3,8-10]. However, there is little information available in literature about the effects of internal and external causes on PEMFC performance for short-term space missions. Internal water management is also a key technology in achieving development of PEMFCs to be used in the low gravity (space environment) operating conditions.

Water generated on the cathode side significantly affects PEMFC behavior and output power in two opposite ways. The polymeric membrane layer needs enough water to maintain good ionic conductivity and lifetime of the cell, whereas abundant water accumulating in the cell will prevent further access of the reactant gas and result in degradations. Therefore, maintaining water content balance within PEMFC has received significant research attention in the past few years [10-16]. Understanding water transport mechanism and gas-liquid two-phase flow phenomenon inside an 
operating PEMFC is an effective method for water management and removal. By utilizing experimental and simulation method, investigations on liquid water transport characteristic inside the flow channel [17-27] have received more progress in the terrestrial gravity circumstance, and have certified that cell behavior is seriously associated with gas-liquid two-phase transport characteristic.

The in-situ visual is a useful method for investigating the gasliquid two-phase flow inside the reactant channels. High-speed camera and transparent PEMFCs are commonly used to obtain a directly understanding of gas-liquid two-phase dynamic in the terrestrial circumstance for engineering application. Given the importance of gravitational level, several researches were conveyed with in-situ visual to explore the cell behavior by changing the orientations of the reactant channels and inflow [4,28-31]. An optical imaging of a transparent cell was taken by Kimball et al. [4] to explore the basic physics of liquid water in PEMFCs with different channel orientations. Water motion showed diverse characteristics with the change in flow channel orientation. The authors showed that water flooding in PEMFCs is gravity dependent. Lu et al. [28] investigated the impact of flow orientation on the two-phase flow dynamics in the cathode flow channel (CFF) of the PEMFC with a parallel field. They found that flow field channels with horizontal orientations are prone to retain more water because of slug flow, non-uniform liquid water distribution, and unstable operation. In a recent research, Nishida et al. [31] employed in-situ visualization techniques to investigate the impacts of wettability and direction of the flow channel on the water transport in an operating fuel cell. Their results showed that, without being disturbed by gravity, a transparent PEMFC placed at the horizontal orientation arrangement of the two-pass serpentine flow field will accelerate liquid water removal out of the cell, especially with highly hydrophilic coating. Moreover, several works were conducted to experimentally and numerically investigate the impact of gravitational level on PEMFC performance by changing the arrangement of fuel cells [5,32-36]. Chen and $\mathrm{Wu}$ [5] performed experiments to explicate the impact of gravitational on liquid water discharge inside the PEMFC by placing the cathode or anode upward. In comparing the performance of fuel cells in different placement positions of the cathode and anode, they found that liquid water discharge inside the fuel cell with a cathode-upward flow field is superior to that inside the anode-upward flow field. Morin et al. [32] analyzed the spectra of liquid content outside the membrane and found that, for a constant current density, the performance of the cell is enhanced for a symmetric configuration when the cathode inlet is placed at the bottom of flow field because of better membrane hydration. Lee et al. [34] also presented the impact of gravitational level on cell polarization characteristics and liquid water discharge phenomenon. Liquid water removal inside the cathode flow channel depended on the flow channel distribution, flow direction, and gas inlet port. Therefore, gravitational force significantly affected the cell behavior. Yu et al. [35] conveyed a group of work to investigate the impact of gravitational level on the cell behavior of an operating PEMFC stack by changing positions of the inlet and outlet of reaction gas. The optimization operating angle and inlet/outlet location were recommended for the design and to operate the fuel cells to improve performance. Najjari et al. [36] also established a numerical computational model to research the impact of gravitational level on dynamic responses and flooding in the cathode of a PEMFC. They considered the mass transport of liquid water and reaction gas inside the GDL in their model. The results indicated that gravitational level has a momentous effect on PEMFC performance at a steady operating regime.

Most of these investigations focused on the impact of gravitational level in a terrestrial gravity circumstance, but gas-liquid twophase flow characteristic in a micro-gravity circumstance was largely neglected in recently. Obviously, burgeoning microgravity multiphase fluid dynamics has shown that gas-liquid two-phase flow in a micro-gravity is quite different from those in a terrestrial gravity circumstance because the gravity level of the former is near zero. Studies on the cell performance of direct methanol fuel cells (DMFCs) [37-41], one of the PEMFCs, in a micro-gravity environment have been conducted. The DMFCs showed different behaviors in different gravity circumstances. Under terrestrial gravity and short-time micro-gravity conditions, a transparent DMFC with parallel flow channel was considered to study the transport phenomenon of the reactant and liquid water in anode [37,38]. The flow pattern of the gas-liquid two-phase in micro-gravity were significantly different from those in the terrestrial gravity environment, especially for bubble size and velocity. Cell performance was deteriorated, while gravity vanished at high current density. In a small liquid-feed DMFC, Guo et al. [38] visually observed twophase flow transport phenomenon in anode side under a microgravity circumstance caused by the drop tower. They compared the flow pattern and bubble size in the vertical flow channel orientation implied that the impact of gravitational level on twophase flow is slight and that bubble expulsion is mainly controlled by the viscous drag. Ye et al. [41] reported that gravity seriously affects the cell performance of DMFCs, especially when the fuel cell is operating at high current density. Moreover, visualization on the two-phase flow transport phenomenon of a PEMFC operating at different conditions was conveyed under the terrestrial gravity and micro-gravity circumstances [42,43]. The cell performance of an operating PEMFC presented in our previous work [43] indicated that because of the impact of gravitational level on the two-phase flow, the cell behavior in a micro-gravity circumstance is obviously different from those in a terrestrial gravity circumstance when the cell operates in low and high current density operating conditions. However, the limitations of our previous study are lack of considering the influence of the flow field configuration in a micro-gravity circumstance. A deficiency of the flow channel configuration meant that the gas-liquid two-phase flow transport characteristic may be significantly affected by the flow field configuration of PEMFCs, especially when the cell was operating in the micro-gravity circumstance.

In general, gravitational level and gas flow channel configuration affect the transport characteristic of the reactant and liquid water in a cathode flow channel and the cell performance of PEMFCs. Paying particular attention to the effect of low gravity (micro-gravity circumstance) on cell behavior is necessary for space application. In this study, we employ the experimental apparatus used in our previous study [43], including an automotive synchronization test system coupled with liquid water visualization, optical imaging record, and cell performance measurements. This work aims to (1) provide insight into two-phase flow transport phenomena of an operating PEMFC under two flow channel orientations from a terrestrial gravity circumstance to micro-gravity circumstance, and then (2) investigate the impact of gravitational level on the transport characteristic of the reactant and liquid water and cell performance of an operating PEMFC.

\section{Experimental}

\subsection{Micro-gravity environment}

The micro-gravity experiment circumstance was provided by a drop tower located at the National Microgravity Laboratory. Fig. 1 illustrates main micro-gravity experiment facilities. In this study, the tested system underwent three stages in once micro-gravity experiment. The drop capsule was firstly placed at the top of the drop tower within where the tested system can operate at a 


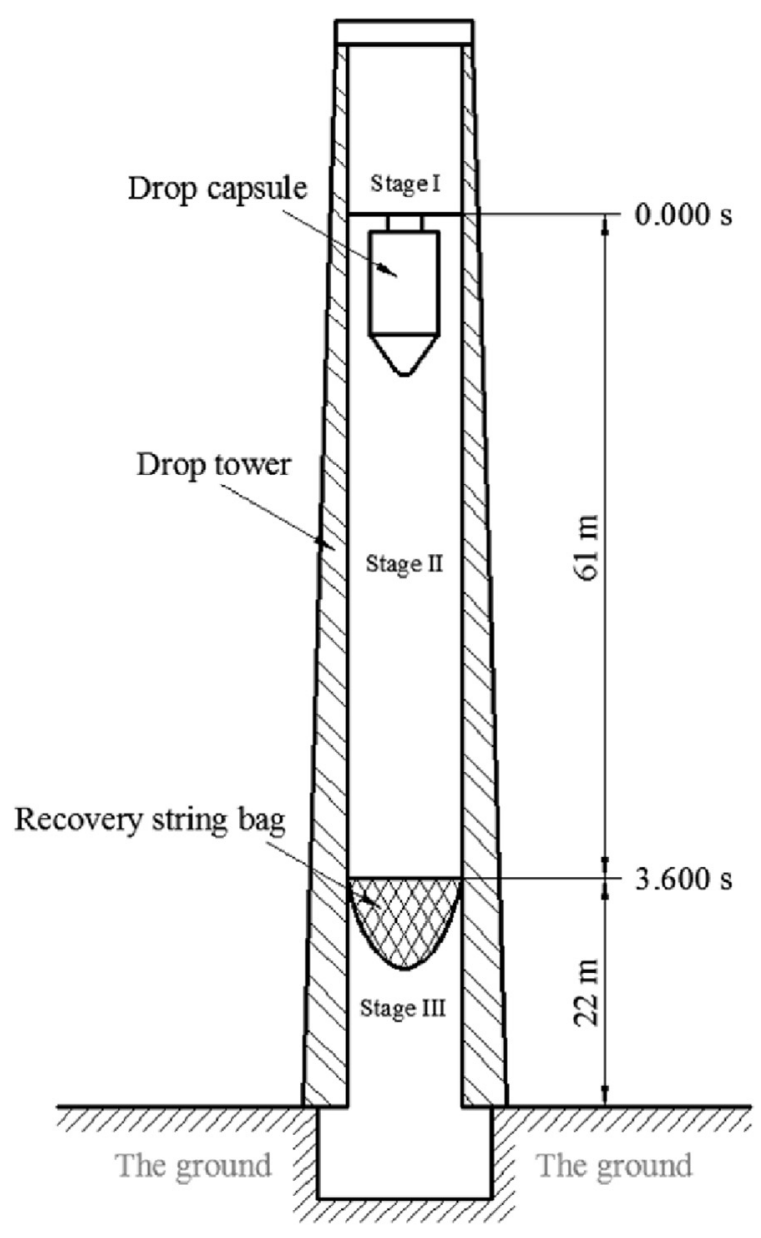

Fig. 1. Micro-gravity experiment facility. terrestrial gravity circumstance, namely, the stage I. After the freefalling, the drop capsule offered a short-time micro-gravity circumstance for the tested system at the stage II. Entering the second stage, tested system obtained a relatively stable microgravity experiment circumstance of $3.6 \mathrm{~s}$ attributed to the effective free-falling height of $83 \mathrm{~m}$. Falling to the vertical height of $61 \mathrm{~m}$, the entire drop capsule and tested system was recovered via a recovery string bag within a safely height of $22 \mathrm{~m}$.

\subsection{Tested system}

Fig. 2 displays the tested system, which consists of a transparent PEMFC, reactant supply system, optical imaging record system, data collection, and signal control system. Before the series of tests, all of the subsystems applied to micro-gravity experiments were uniformly placed at the test-bed within the drop capsule. The test-bed was also checked by a balance system to maintain the balance of the PEMFC during the free-falling stage.

The transparent PEMFC structure for this study is similar to that one in our previous work [43]. In brief, the membrane electrode assembly (MEA) with a $25 \mathrm{~cm}^{2}$ active area was caught in the middle between the anode and cathode GDLs. The Pt loadings in the anode and cathode electrodes were both $1 \mathrm{mg} \mathrm{cm} \mathrm{cm}^{-2}$. Two graphite current-collector plates were machined to form a single serpentine flow field ( $2 \mathrm{~mm}$ in width, $2 \mathrm{~mm}$ in depth) at both the anode and cathode in the same way. In the cathode side, a transparent plexiglass plate was covered outside of the flow field for optical access. An aluminum alloy end plate with an opening window was machined on the cathode to allow direct observation of the liquid water and flow behavior inside flow channels.

Considering the space limitations, the reactant supply system without a humidifier was set up for this study. High pure gases of the $\mathrm{H}_{2}$ and $\mathrm{O}_{2}$ were employed as reactant gases for current experiments. Gas reactants feeding was regulated at a constant rate for two tested orientations. An optical imaging record was the main device of the video and photo imaging system, which was taken to capture and record the images of gas-liquid two-phase flow

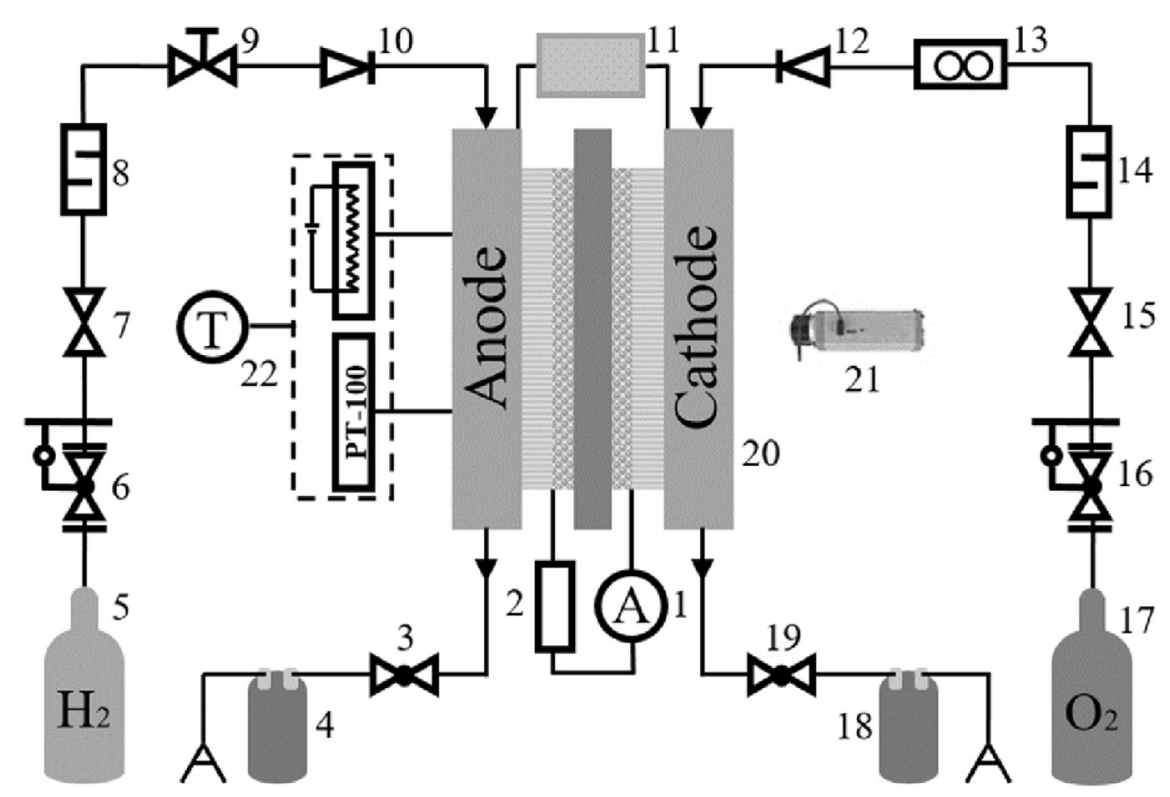

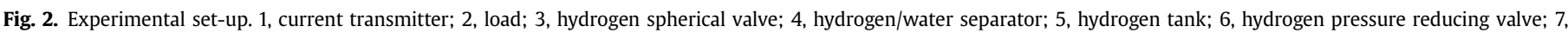

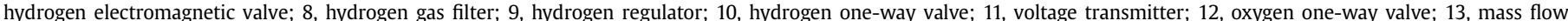

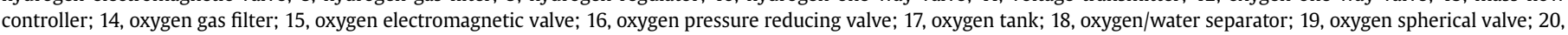
transparent fuel cell; 21, high speed video camera; 22, temperature controller unit. 


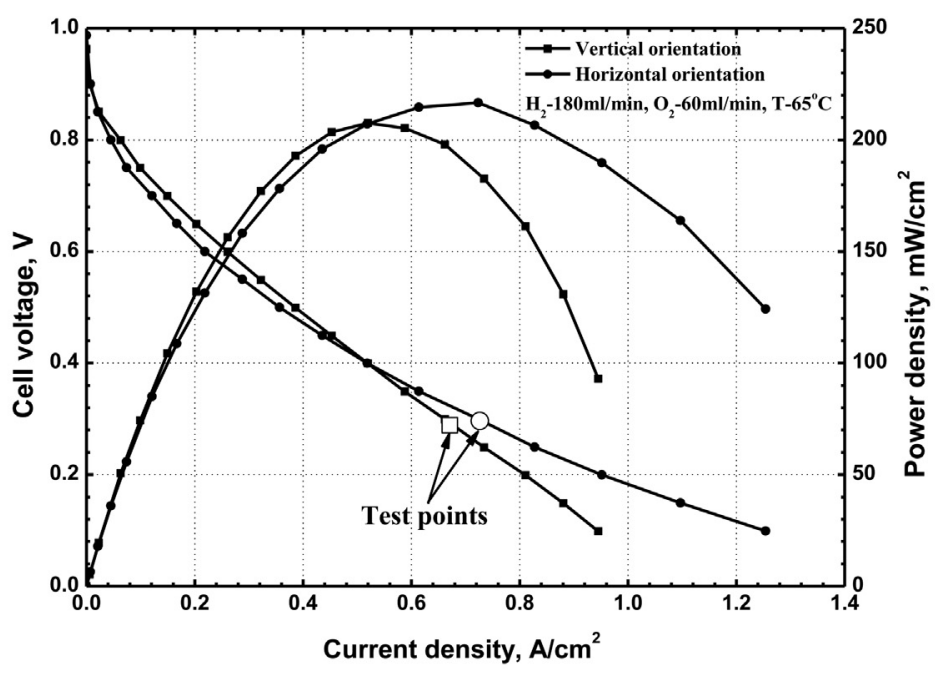

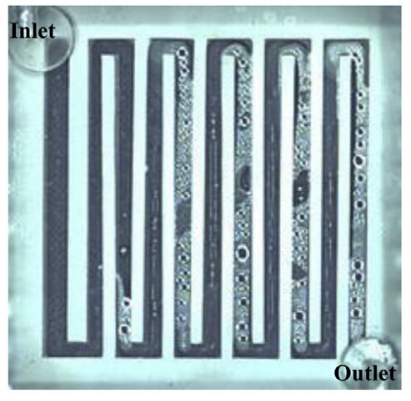

(1) Vertical flow channel orientation operating condition

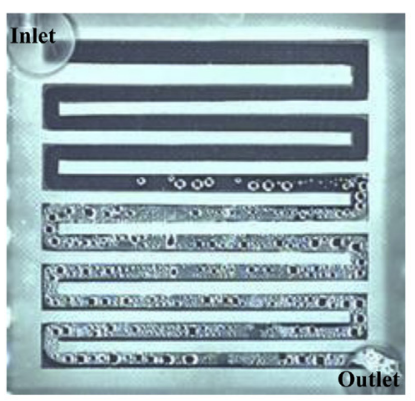

(2) Horizontal flow channel orientation operating condition

Fig. 3. The performance and operating conditions of the transparent PFMFC under the terrestrial gravity circumstance.

transport phenomenon. The capturing and recording speeds of the imaging system can achieve at $1 / 1000 \mathrm{~s}$ and 1000 frames $\mathrm{s}-1$ respectively. Auxiliary lighting was provided by light-emitting diodes to capture a high-quality images. An automotive synchronization control system coupled with the data collection and signal control systems was regulated via a microcomputer. It utilized a multifunction data logger system to synchronously collect and store data, including gas flow rates, running temperature, current and voltage of the cell. Gravitational level caused by falling the drop capsule was also qualitatively collected. More detail information on experimental setup refer to our previous work in Ref. [43].

\subsection{Experiment specification}

To be credible and effective, the cell performances were repeatedly tested at the ground laboratory by using the microgravity tested system for half a month. The cell was operated at $65{ }^{\circ} \mathrm{C}$. The flow rates of the dry oxidant and fuel reactant were 60 and 180 SCCM, respectively. A load with a fixed resistance was used as the external circuit of the PEMFC. In this study, the transparent PEMFC was tested in two operating orientations: horizontal flow channel and vertical flow channel. Fig. 3 depicts the performance curves (cell voltage versus current density, I-V curve) of the tested PEMFC in a terrestrial gravity circumstance for micro-gravity experiment. After those tests, the operating behavior of the PEMFC was investigated from a terrestrial gravity to a micro-gravity circumstances under two operating conditions.

In one micro-gravity experiment, the tested PEMFC was firstly operating for more than $1.5 \mathrm{~h}$ at the top of the drop tower under terrestrial gravity condition. The cell performance of the tested points was measured in the operating conditions of the vertical and horizontal flow channel orientations, and was marked as two hollow symbols in Fig. 3. The two tested points match well with the performance curves. This result manifests a good reproducibility of the terrestrial gravity experiments in PEMFC. The tested cell had already achieved a stable operating state in the terrestrial gravity conditions before entering into micro-gravity conditions.

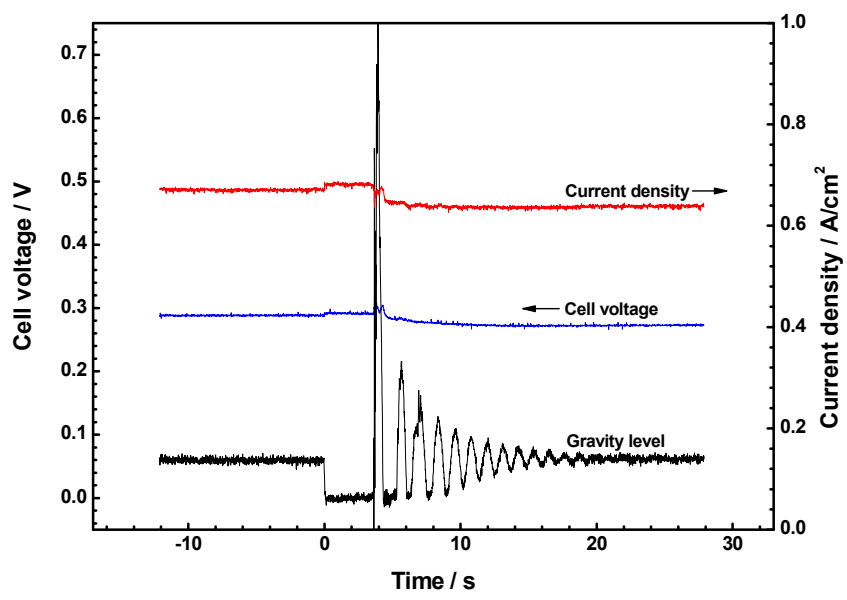

Fig. 4. PEMFC behavior underwent three gravitational levels under the vertical flow channel orientation operating condition. 

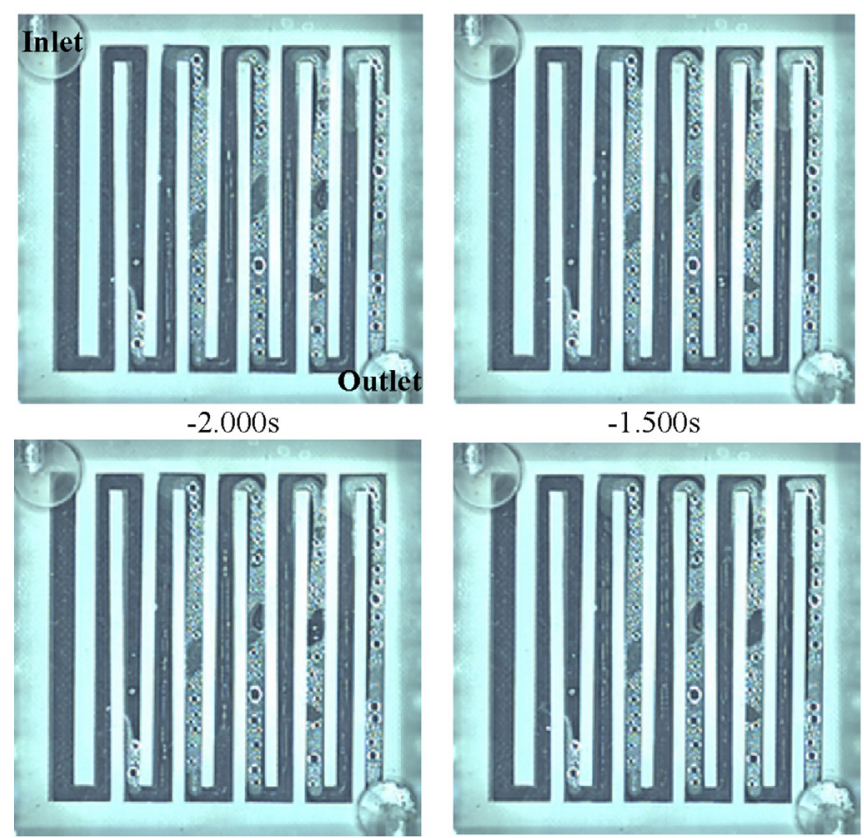

$-0.500 \mathrm{~s}$

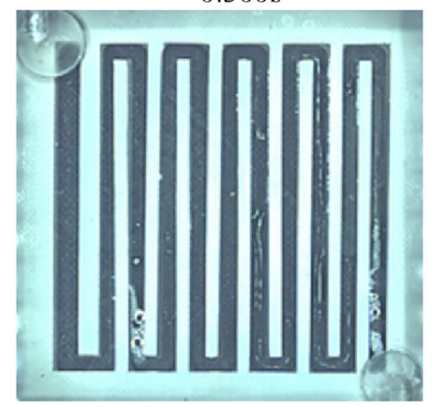

$1.000 \mathrm{~s}$

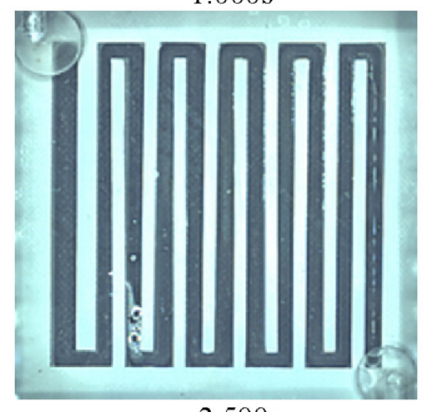

$2.500 \mathrm{~s}$
$-1.500 \mathrm{~s}$

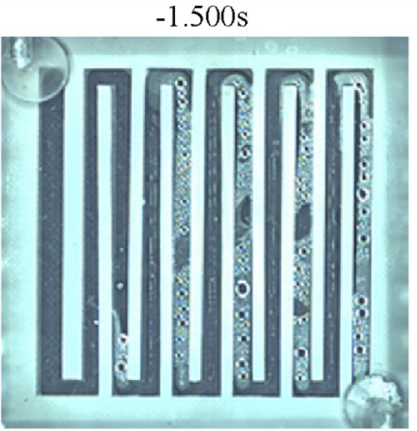

$0.000 \mathrm{~s}$

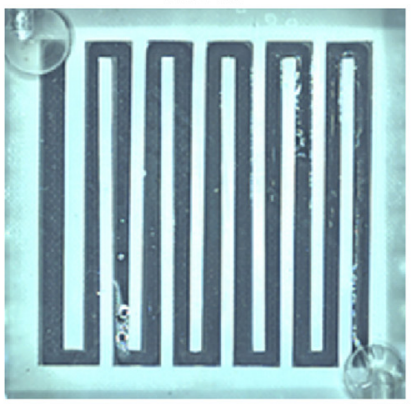

$1.500 \mathrm{~s}$

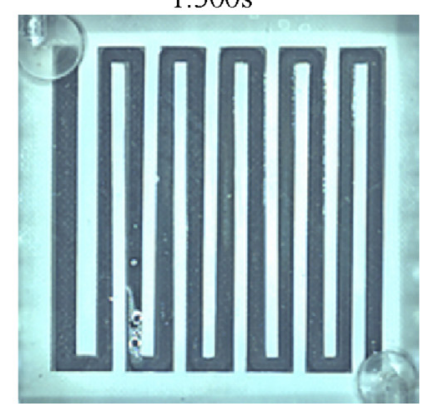

$3.000 \mathrm{~s}$

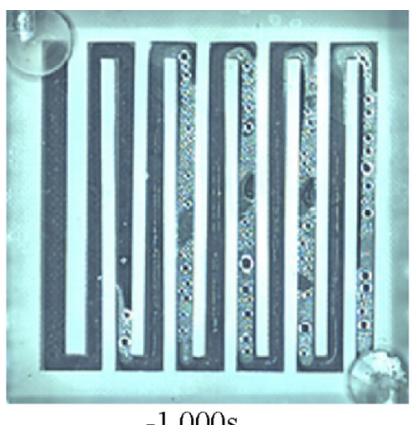

$-1.000 \mathrm{~s}$

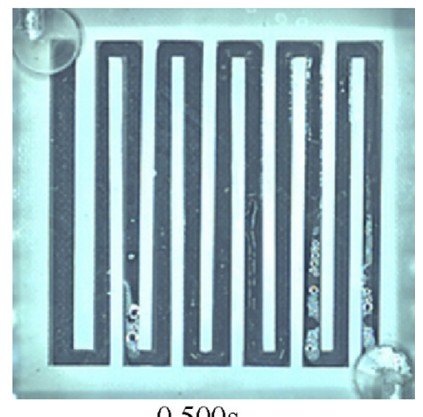

$0.500 \mathrm{~s}$
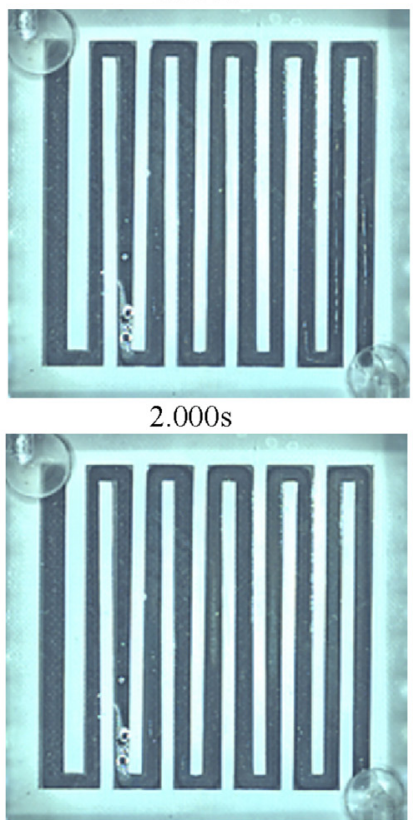

$3.500 \mathrm{~s}$

Fig. 5. Two-phase flow from a terrestrial gravity to a micro-gravity circumstances under the vertical flow channel orientation operating condition.

Given the difference of test results, the initial time of the freefalling for the drop capsule was recognized as the cut-off point of the fuel cell operating from a terrestrial gravity circumstance (stage I) to a micro-gravity circumstance (stage II), as shown in Fig. 1. A 10 s data collection was set to collect data in the terrestrial gravity, and another $40 \mathrm{~s}$ was taken to collect data in the short-term microgravity environment (including stages I and II). In Fig. 3, two images present the in-situ optical images of the gas-liquid two-phase flow phenomenon within the CFF under these two flow channel orientations. Positioning the single serpentine PEMFC gas channel vertically results in more water accumulation and flow maldistribution in the upward movement flow channels. These outcomes are in agreement with the findings in Refs. [31,34] that fuel cell performance in a horizontal orientation is more advantageous than that in a vertical operation for a PEMFC with a single serpentine flow field in an earth environment. This is because gravity is conducive to water moving to the bottom of the flow field. Experiment results presented in this study was chosen at random from one of the results in several experiments. Each experiment result showed good repeatability.

\section{Results and discussion}

\subsection{Operating condition of vertical flow channel orientation}

Fig. 4 presents the electrical performances of the operating cell from a terrestrial gravity circumstance to a micro-gravity circumstance at the operating condition of vertical flow channel 
orientation. The black curve qualitatively depicts the gravitational level during the whole experiment duration time. In one microgravity experiment, the cell goes through three gravity level environments. Before the drop capsule was released, the cell stably operated in terrestrial gravity. After the drop capsule was released, it supplied a $3.6 \mathrm{~s}$ relatively stable micro-gravity circumstance for the operating PEMFC via the free-falling. After a $3.6 \mathrm{~s}$ micro-gravity circumstance, the relatively stable gravitational level was broken caused by the safety string bag. In Fig. 4, the synchronous measurement results show that the current density and cell voltage rose rapidly as the gravity shifted from a terrestrial gravity circumstance to a micro-gravity circumstance.

By using synchronous measurement and photograph technology, the cell performance and in-situ optical images of the twophase flow inside CFF are achieved from a terrestrial gravity circumstance to a micro-gravity circumstance at the vertical flow channel orientation operating condition. Fig. 5 displays the visual results of the two-phase flow transport phenomenon inside CFF. Fig. 6 depicts that the cell performance varies with gravitational level caused by changed operating environment in gravity at the vertical flow channel orientation. A time of $0.000 \mathrm{~s}$, as shown in Fig. 1, is denoted as the cut-off point of the gravitational level caused by free-falling in the following studies. The time before $0.000 \mathrm{~s}$ is negative, which means the operating condition in the terrestrial gravity. The time after $0.000 \mathrm{~s}$ is positive, which means the operating condition in the micro-gravity. The measurement values of cell voltage, current and power density, and visual images are synchronously displayed every $0.500 \mathrm{~s}$. Considering the time limitation of short-time micro-gravity circumstance, four images within a $2 \mathrm{~s}$ video was chosen to show the optical images in the terrestrial gravity circumstance, and another seven images within a $3.5 \mathrm{~s}$ video was taken to present the optical images in the microgravity circumstance in current paper.

Fig. 5 reveals that the two-phase transport phenomena in the CFF are distinguished between the terrestrial gravity and microgravity circumstances because of the change in gravitational level. In the normal gravity environment, inertial effect is the major factor for the two-phase movement, and gravity is another important factor that cannot be ignored. In a long part of the flow channel inlet, only small amounts of liquid droplets occur in the initial part of the flow channel as a result of the larger inertial effect of oxygen. An upward movement of the liquid water is observed with the increase in serpentine flow channel length. Liquid water is separated from the gas phase because of the weak inertial effect of this phase. Finally, because of the impact of gravity on the liquid water, the water falls down and forms into a liquid column at the bottom of the serpentine flow channels with an upward movement of the gas phase. Meanwhile, in the flow channels with a downward movement of the gas phase, a few liquid droplets that separated from the gas phase are hung in the transparent plate as a result of the weak inertial effect of the gas phase. Therefore, liquid column and flooding occur in the flow channel with the upward movement of the reactant gas in the terrestrial gravity. However, upon entering the micro-gravity circumstance, the gravity effect on the two-phase flow rapidly weakens because the gravity level is almost zero, as shown in Fig. 4. Inertial effect have a major function in this phenomenon. As shown in Fig. 5, the liquid water that accumulated at the bottom of the flow channel with the upward movement of the reactant gas is pushed by the oxygen to continuous removal toward the outlet of the fuel cell within the micro-gravity circumstance of $3.000 \mathrm{~s}$ (Fig. 5, from $0.000 \mathrm{~s}$ to $3.000 \mathrm{~s}$ ). The similar water removal phenomenon can be found in Guo et al.'s work [43], but the water removal duration in this study are obviously longer than that in our previous work. This is because that flow rate of the oxygen in previous work is the twice of this work,

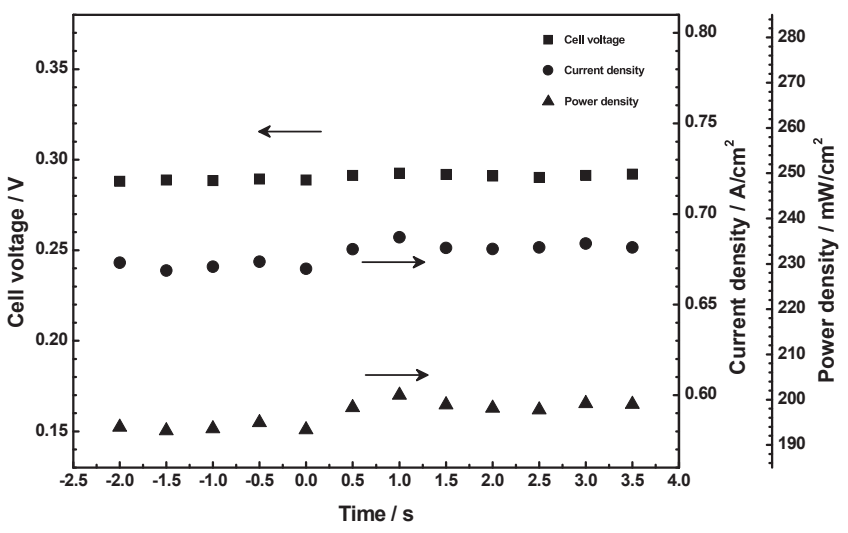

Fig. 6. The performance of the PEMFC from a terrestrial gravity to a micro-gravity circumstances under the vertical flow channel orientation operating condition.

and higher flow rate could be helpful for water discharge. Furthermore, liquid droplets are rapidly coalesced by the removed liquid water. A stable gas-liquid phase interface is formed along with the movement of the reactant and product. The liquid phase separated from the gas phase cannot be observed when liquid water and liquid droplets are moved out of the cathode flow channels. Therefore, the water flooded area in the CFF is distinctly reduced with the discharge of the liquid water. A reasonable water removal is beneficial for enhancing the mass transport of the reactant gas and electrochemical reaction inside the cathode electrode of the PEMFC. Hence, the characteristic of the cell is optimized in the micro-gravity operating condition, as shown in Fig. 6. The fact that optimization mass transport of the oxygen feeding can facilitate the cell performance of PEMFCs has been confirmed by numerous publications [5,20and44]. During the entire test, none of the operating conditions were changed except for gravity, when the operating fuel cell shifted from a terrestrial gravity circumstance to a micro-gravity circumstance. Thus, the variation in two-phase flow is related to gravitational level, and water removal in the microgravity circumstance is easier than that in the terrestrial gravity circumstance under the vertical flow channel orientation operating condition.

\subsection{Operating condition of horizontal flow channel orientation}

Corresponding to cell performance under the horizontal flow channel orientation operating condition, Fig. 7 presents the

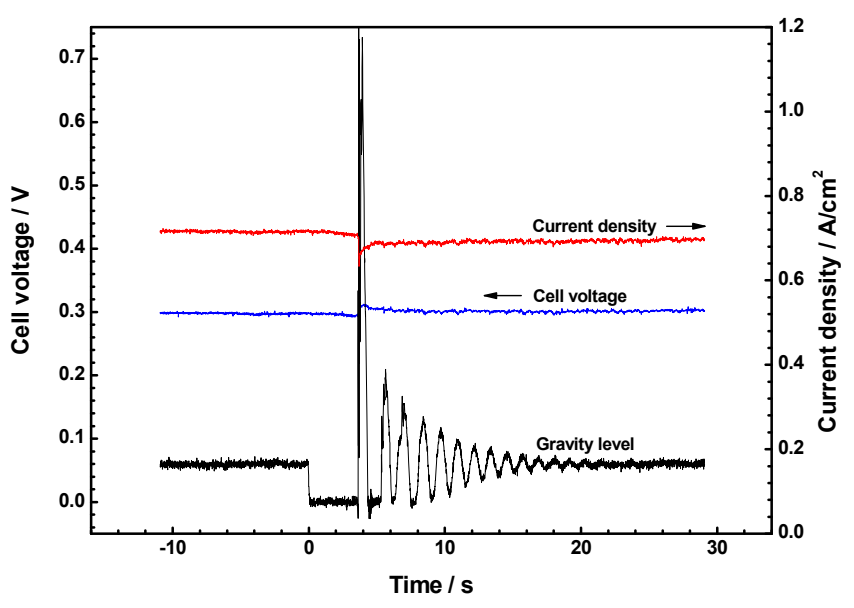

Fig. 7. PEMFC behavior underwent three gravitational levels under the horizontal flow channel orientation operating condition. 

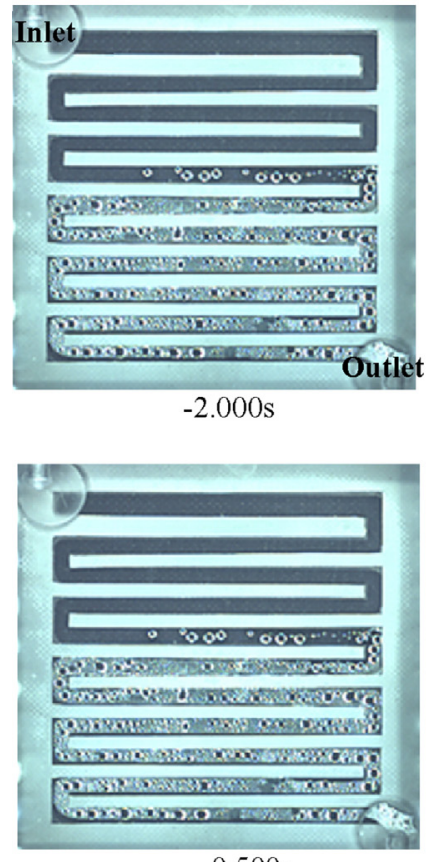

$-0.500 \mathrm{~s}$
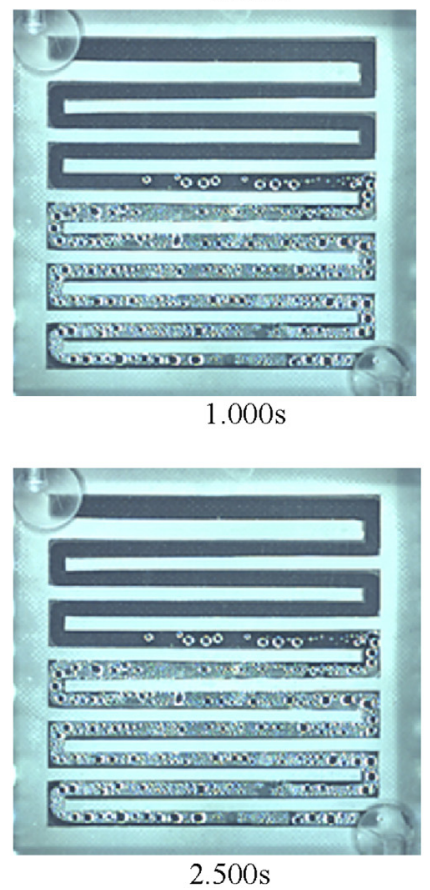

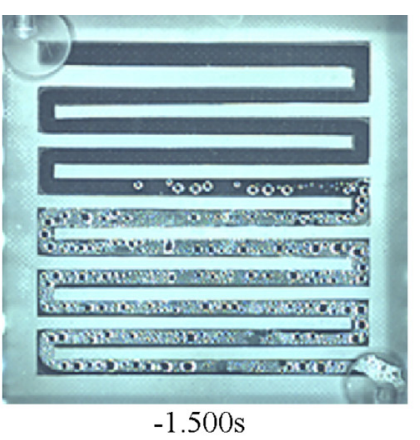

$-1.500 \mathrm{~s}$

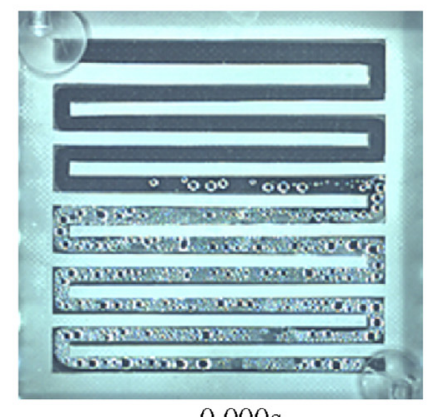

$0.000 \mathrm{~s}$

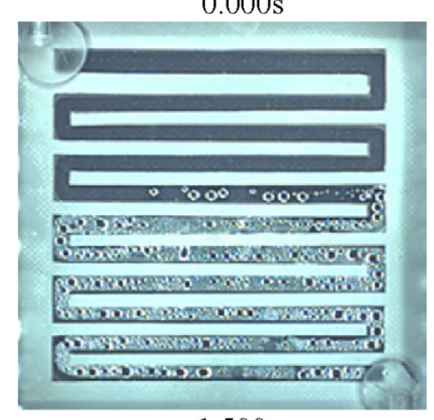

$1.500 \mathrm{~s}$

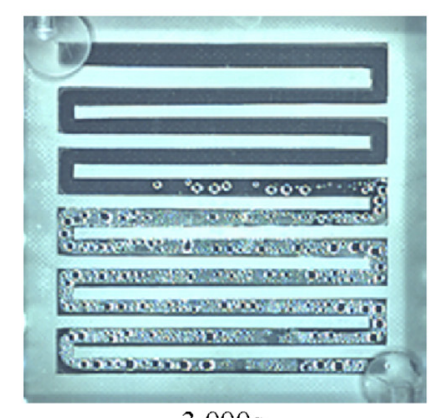

$3.000 \mathrm{~s}$
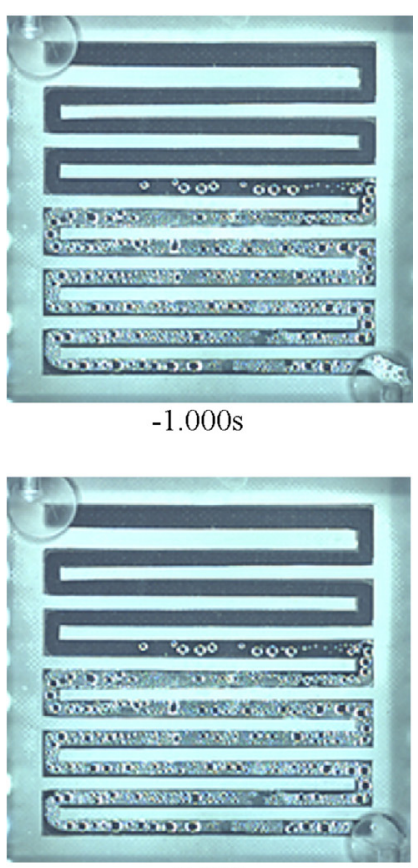

$0.500 \mathrm{~s}$
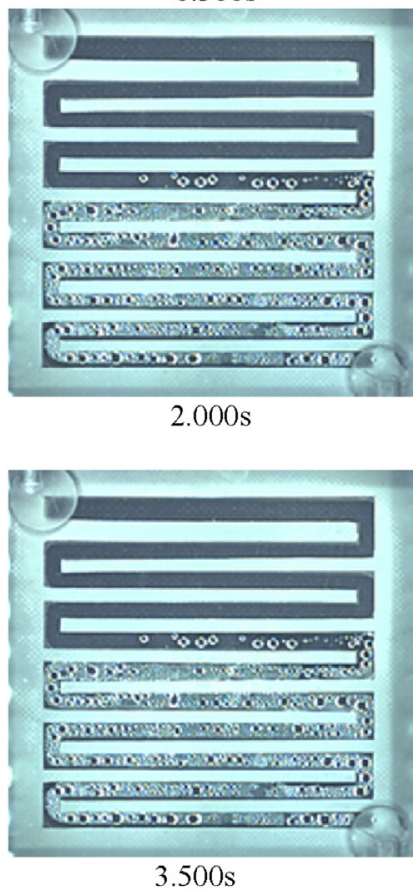

Fig. 8. Two-phase flow from a terrestrial gravity to a micro-gravity circumstances under the horizontal flow channel orientation operating condition.

electrical performances of the operating cell from a terrestrial gravity circumstance to a micro-gravity circumstance. The gravity level curve shows that the operating PEMFC also goes through three gravity level environments under the horizontal flow channel orientation operating condition. However, no significant change in cell performance is observed after the cell operated in the surroundings of the micro-gravity from the terrestrial gravity. This result is different from that with a vertical flow channel orientation (Fig. 4).

Cell performances and optical images of two-phase flow side CFF are synchronously measured and photographed from a terrestrial gravity circumstance to a micro-gravity circumstance under the horizontal flow channel orientation operating condition, as shown in Fig. 8. Fig. 9 demonstrates that the performance of the fuel cell varies with gravitational level caused by changing operating environment in gravity at the horizontal flow channel orientation. The denoted time at the horizontal flow channel orientation is the same as that under the vertical flow channel orientation. Fig. 8 shows that the significant difference of the twophase transport phenomenon is not observed in the CFF under the horizontal flow channel orientation operating condition when the transparent PEMFC operates from a terrestrial gravity circumstance to a micro-gravity circumstance. In the terrestrial gravity circumstance, no liquid water or liquid droplet is found in a very long part 


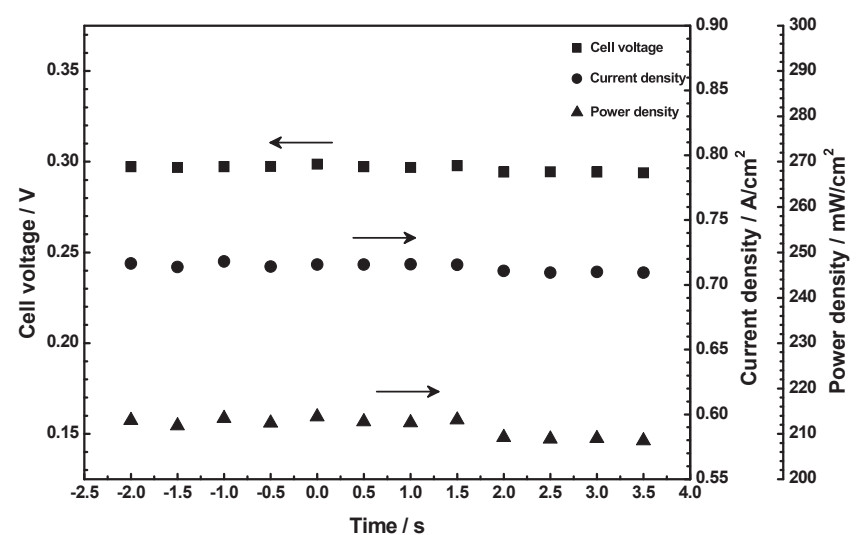

Fig. 9. The performance of the PEMFC from a terrestrial gravity to a micro-gravity circumstances under the horizontal flow channel orientation operating condition.

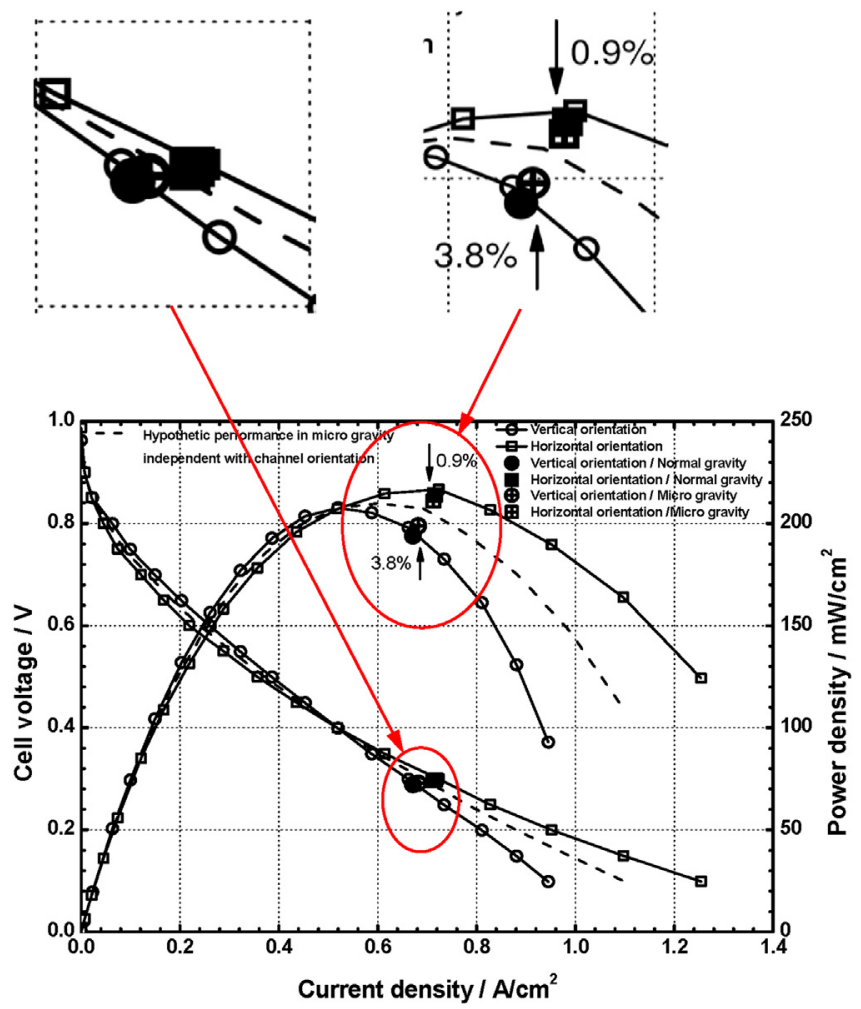

Fig. 10. The performance of the PEMFC from a terrestrial gravity to a micro-gravity circumstances under the vertical and horizontal flow channel orientation operating conditions.

of the inlet of the flow channel owning to a larger inertial effect of a high oxygen flow rate. The increase in serpentine flow channel length results in the liquid droplets gradually separated from gas phase because of weak inertial effect of this phase. Parts of liquid droplets are hung in the transparent plate, whereas the generated water accumulates at the foot of the horizontal channels as a result of the gravity, as shown in Fig. 8. Otherwise, gravity promotes liquid water gathered at the bottom of the horizontal flow channels to move into the outlet of the fuel cell because there is no upward flow passage in flow channel. Thus, the water columns necessary to block off flow channels are difficult to be formed in the terrestrial gravity circumstance. However, Fig. 8 shows that liquid water formed in micro-gravity is prone to stay in the CFF when the operating environment shifts into a micro-gravity condition. This outcome is attributed to gravity being reduced nearly to zero and the surface tension becoming relatively stronger. Thus, the liquid water accumulated in the micro-gravity circumstance is more than that in the terrestrial gravity circumstance under the horizontal flow channel. The excess liquid water staying in the CFF will flood flow channels, and will eventually deteriorate cell performance if the cell operates longer in the micro-gravity circumstance. In this study, the microgravity condition duration (3.6 s) is too short to allow observation of the liquid water flooding phenomena. A drop trend of cell performance approves this water flooding trend, as shown in Fig. 9. This trend implies that the liquid water generated inside the PEMFC under horizontal flow channel orientation operating condition is difficult to move out of the flow channel during the microgravity environment and will deteriorate cell behavior.

\subsection{Cell performance with varying gravity levels}

Fig. 10 shows the performance curves (I-V curves) of the transparent PEMFC operated in the two CFF orientations with the conditions of constant load resistance, feeding rates of $\mathrm{H}_{2}$ and $\mathrm{O}_{2}$, cell temperature, and terrestrial gravity. The hollow and solid symbols present the test results before and after the cell operated in micro-gravity circumstance. The values of cell voltage, current and power densities are all the arithmetical averages of values measured in the whole experiments. The tested points of the cell in terrestrial gravity match the cell performance perfectly, which implies that the PEM fuel cell conveyed in current study operated stably. Notably, gravity is the only changed condition for the two operating conditions of flow channel orientations. Fig. 10 shows that the cell performance in the micro-gravity circumstance is different from that in the terrestrial gravity circumstance, either under the vertical or horizontal flow channel orientation operating conditions. Under the vertical flow channel orientation operating condition, cell performance is promoted by 3.8\% after the cell operated in the micro-gravity. Cell performance improved by $4.6 \%$ was obtained in our previous study [43], which is higher than that in this study. This is because shorter water removal duration in previous study is more conducive to promote mass transfer and enhance the cell performance as previous analyzed. However, under the horizontal flow channel orientation operating condition, the cell performance is somewhat deteriorated in micro-gravity. Therefore, the impact of the micro-gravity circumstance on cell behavior is obvious, and the construction of the flow field leads to diverse cell performance from a terrestrial gravity circumstance to a micro-gravity circumstance. Given the limited micro-gravity circumstance duration, the $\mathrm{I}-\mathrm{V}$ characteristics curves of the cell operated in micro-gravity cannot be obtained in this paper. A longterm micro-gravity circumstance will supply additional information on the two-phase evolution and operating behavior of PEMFC in a long-time space mission. More contributions are also desired to understand the PEMFC operating behavior in a low gravity circumstance, especially for internal evolution mechanism of the gas-liquid two-phase inside the fuel cells, as well as to seek an optimization scheme on the efficient water removal and stably operating of PEMFCs for short-time space application.

\section{Conclusions}

Under the vertical and horizontal flow channel orientation operating conditions, in-situ optical images of the gas-liquid twophase transport phenomenon and the cell performance of the PEMFC from a terrestrial gravity circumstance to a short-term micro-gravity circumstance were studied in current paper. The major experimental conclusions are as follows: 
1. Gravitational level has diverse effects on water removal and cell performance of the PEMFC with different flow channels.

2. Under the vertical flow channel orientation operating condition, liquid water flooding occurs at the bottom of the flow channel with an upward movement of reactant gas in the terrestrial gravity circumstance. However, owning to a sharply vanish of the gravity, the liquid droplets and accumulated liquid water is pushed by the oxygen to continuous removal toward the outlet of the cell to alleviate flooding phenomenon in a $3.6 \mathrm{~s}$ microgravity circumstance.

3. Under the horizontal flow channel orientation condition, water flooding phenomenon does not take place at the bottom of the flow channel in terrestrial gravity circumstance. During the micro-gravity experiment duration, the generated water is too hard to be discharged to flood the cathode flow channel in the microgravity environment.

4. After the cell operates in a $3.6 \mathrm{~s}$ micro-gravity circumstance, cell performance and water removal are enhanced under vertical flow channel orientation operating condition, but slightly deteriorated under the horizontal flow channel orientation operating condition.

\section{Acknowledgements}

The authors wish to appreciate the National Natural Science Foundation of China (Grant No. 51476003) for the financial support. The authors gratefully thank Mr. Xiaohui Wu, Mr. Shixin Wan and Mr. Minggang Wei for kindly help and discussion, and thank Ms. Qing GUO for the typesetting.

\section{References}

[1] Sone Y, Ueno M, Naito H, Kuwajima S. One kilowatt-class fuel cell system for the aerospace applications in a micro-gravitational and closed environment. J Power Sources 2006;157:886-92.

[2] Chen HH, Pei PC, Song M. Lifetime prediction and the economic lifetime of proton exchange membrane fuel cells. Appl Energ 2015;142:154-63.

[3] Sone Y, Ueno M, Kuwajima S. Fuel cell development for space applications: fuel cell system in a closed environment. J Power Sources 2004;137:269-76.

[4] Kimball E, Whitaker T, Kevrekidis YG, Benziger JB. Drops, slugs, and flooding in polymer electrolyte membrane fuel cells. AICHE J 2008;54:1313-32.

[5] Chen SZ, Wu YH. Gravity effect on water discharged in PEM fuel cell cathode. Int J Hydrogen Energy 2010;35:2888-93.

[6] Carton JG, Olabi AG. Design of experiment study of the parameters that affect performance of three flow plate configurations of a proton exchange membrane fuel cell. Energy 2010;35:2796-806.

[7] San FGB, Isik-Gulsac I, Okur O. Analysis of the polymer composite bipolar plate properties on the performance of PEMFC (polymer electrolyte membrane fuel cells) by RSM (response surface methodology). Energy 2013;55:1067-75.

[8] St-Pierre J, Jia NY. Successful demonstration of ballard PEMFCs for space shuttle applications. J New Mater Electrochem Syst 2002;5:263-71.

[9] Sone Y, Ueno M, Kuwajima S. Fuel cell development for space applications in a micro-gravitational and closed environment. Electrochemistry 2003;71: 938-43.

[10] Sone Y, Ueno M, Naito H, Kuwajima S. Stable performance of a polymer electrolyte fuel cell system in a closed environment without external humidification. Electrochemistry 2006;74:768-73.

[11] Xing L, Liu XT, Alage T, Kumar R, Mamlouk M, Scott K. A two-phase flow and non-isothermal agglomerate model for a proton exchange membrane (PEM) fuel cell. Energy 2014;73:618-34.

[12] Banerjee R, Kandlikar SG. Two-phase flow and thermal transients in proton exchange membrane fuel cells - a critical review. J Power Sources 2015;40: 3990-4010.

[13] Kang S. Quasi-three dimensional dynamic modeling of a proton exchange membrane fuel cell with consideration of two-phase water transport through a gas diffusion layer. Energy 2015;90:1388-400.

[14] Rakhshanpouri S, Rowshanzamir S. Water transport through a PEM (proton exchange membrane) fuel cell in a seven-layer model. Energy 2013;50: $220-31$.

[15] Cordiner S, Lanzani SP, Mulone V. Polymer electrolyte fuel cell design based on three-dimensional computational fluid dynamics mode. J Fuel Cell Sci Technol 2009;6:02131011-4.

[16] Cordiner S, Lanzani SP, Mulone V. 3D effects of water-saturation distribution on polymeric electrolyte fuel cell (PEFC) performance. Int J Hydrogen Energy 2011:36:10366-75.

[17] Kumar PM, Parthasarathy V. A passive method of water management for an air-breathing proton exchange membrane fuel cell. Energy 2013;51:457-61.

[18] Carton JG, Lawlor V, Olabi AG, Hochenauer C, Zauner G. Water droplet accumulation and motion in PEM (Proton Exchange Membrane) fuel cell minichannels. Energy 2012;39:63-73.

[19] Chiu HC, Jang JH, Yan WM, Li HY, Liao CC. A three-dimensional modeling of transport phenomena of proton exchange membrane fuel cells with various flow fields. Appl Energy 2012;96:359-70.

[20] Qin YZ, Du Q Yin Y, Jiao K, Li XG. Numerical investigation of water dynamics in a novel proton exchange membrane fuel cell flow channel. J Power Sources 2013;222:150-60.

[21] Wan ZM, Liu J, Luo ZP, Tu ZK, Liu ZC, Liu W. Evaluation of self-water-removal in a dead-ended proton exchange membrane fuel cell. Appl Energy 2013;104: $751-7$.

[22] Jiao K, Bachman J, Zhou Y, Park JW. Effect of induced cross flow on flow pattern and performance of proton exchange membrane fuel cell. Appl Energy 2014; $115: 75-82$.

[23] Ferreira RB, Falcao DS, Oliveira VB, Pinto AMFR. Numerical simulations of twophase flow in an anode gas channel of a proton exchange membrane fuel cell. Energy 2015;82:619-28.

[24] Hussaini IS, Wang CY. Visualization and quantification of cathode channel flooding in PEM fuel cells. J Power Sources 2009;187:444-51.

[25] Ramiar A, Mahmoudi AH, Esmaili Q, Abdollahzadeh M. Influence of cathode flow pulsation on performance of proton exchange membrane fuel cell with interdigitated gas distributors. Energy 2016:94:206-17.

[26] Kim HY, Jeon S, Song M, Kim K. Numerical simulations of water droplet dynamics in hydrogen fuel cell gas channel. J Power Sources 2014;246:679-95.

[27] Coeuriot V, Dillet J, Maranzana G, Lottin O, Didierjean S. An ex-situ experiment to study the two-phase flow induced by water condensation into the channels of proton exchange membrane fuel cells (PEMFC). Int J Hydrogen Energy 2015;40:7192-203.

[28] Lua Z, Kandlikara SG, Ratha C, Grimma M, Domigana W, Whitea AD, et al. Water management studies in PEM fuel cells, part II: ex situ investigation of flow maldistribution, pressure drop and two-phase flow pattern in gas channels. Int J Hydrogen Energy 2009;34:3445-56.

[29] Kotaka T, Tabuchi Y, Pasaogullari U, Wang CY. Impact of interfacial water transport in PEMFCs on cell performance. Electrochim Acta 2014;146:618-29.

[30] Banerjee R, Kandlikar SG. Liquid water quantification in the cathode side gas channels of a proton exchange membrane fuel cell through two-phase flow visualization. J Power Sources 2014;247:9-19.

[31] Nishida K, Taniguchi R, Ishizaki Y, Tsushima S, Hirai S. Impacts of channe wettability and flow direction on liquid water transport in the serpentine flow field of a polymer electrolyte fuel cell. J Power Sources 2015;275:447-57.

[32] Kimball E, Benziger JB, Kevrekidis YG. Effects of GDL structure with an efficient approach to the management of liquid water in PEM fuel cells. Fuel Cells 2010;10:530-44.

[33] Morin A, Xu FN, Gebel G, Diat O. Influence of PEMFC gas flow configuration on performance and water distribution studied by SANS: evidence of the effect of gravity. Int J Hydrogen Energy 2011;36:3096-109.

[34] Lee JC, Shay T, Chang SK. Orientation-dependent performance of portable proton exchange membrane fuel cells. J Fuel Cell Sci Technol 2011;8:031007.

[35] Yu Y, Tu ZK, Zhan ZG, Pan M. Gravity effects on the performance of PEM fue cell stack with different gas manifold positions. Int J Energy Res 2012;36: 845-55.

[36] Najjari M, Khemili F, Nasrallah SB. The effects of the gravity on transient responses and cathode flooding in a proton exchange membrane fuel cell. Int J Hydrogen Energy 2013;38:3330-7.

[37] Guo H, Zhao JF, Lv CP, Wan SX, Wu F, Ye F, et al. Experimental study of fuel cells performance in short term microgravity condition. J Eng Thermophys 2008;29:865-7 [in Chinese].

[38] Guo H, Zhao JF, Ye F, Wu F, Lv CP, Ma CF. Two-phase flow in fuel cells in short term microgravity condition. Microgravity Sci Technol 2008;20:265-9.

[39] Zhao JF, Guo H, Ye F, Wan SX, Wei MG, Wu F, et al. Experimental study on two phase flow and power performance of DMFC utilizing the drop tower Beijing. Chin J Space Sci 2008;28:17-21 [in Chinese].

[40] Guo H, Wu F, Ye F, Zhao JF, Wan SX, Lv CP, et al. Two-phase flow in anode flow field of a small direct methanol fuel cell in different gravities. Sci China Ser E 2009;52:1576-82.

[41] Ye F, Wu F, Zhao JF, Guo H, Wan SX, Lv CP, et al. Experimental investigation of performance of a miniature direct methanol fuel cell in short-term microgravity. Microgravity Sci Technol 2010;22:347-52.

[42] Guo H, Zhao JF, Ye F, Wan SX, Ma CF. Experimental study of performance of proton exchange membrane fuel cells in short-term microgravity condition. J Eng Thermophys 2009;30:1376-8 [in Chinese].

[43] Guo H, Liu X, Zhao JF, Ye F, Ma CF. Experimental study of two-phase flow in a proton exchange membrane fuel cell in short-term microgravity condition. Appl Energy 2014;136:509-18.

[44] Eikerling M. Water management in cathode catalyst layers of PEM fuel cells-a structure-based model. J Electrochem Soc 2006;153:E58-70. 